253 versos $^{8}$. Nuestro entremés, en cambio, consta sólo de 118 versos; fuera del Pistraco, evidentemente incompleto, sólo El marido flemático (que procede de la misma Navidad) es de extensión tan reducida.

Me parece indudable, tanto por la brevedad extraordinaria de la pieza como por su carácter de sátira personal, tan ajeno a Quiñones de Benavente, que Los sacristanes Cosquillas y Talegote no es obra suya ${ }^{9}$. ¿De quién, pues, será? La pregunta no es fácil de contestar. Ruiz de Alarcón tenía muchos enemigos. Lo que sabemos de Talegote -que era muy alto y gordo- no es base suficiente para identificarlo; en todo caso, es poco probable que el autor del entremés se presentara en escena a sí mismo. Doña Blanca de los Ríos, sin parar mientes en el elemento satírico del entremés, lo ha atribuído a Tirso. Se basa en el hecho ya aludido de que unos versos de este entremés aparecen también en el entremés $E l$ gabacho, impreso como anónimo en la pleiteada Segunda parte de Tirso de Molina; deduce que las dos piezas proceden de la misma mano ${ }^{10}$. El plagio es evidente, pero no lo es tanto la conclusión: Bonilla, que también nota la coincidencia de versos, no vacila en atribuir El gabacho a Tirso y Los sacristanes... a Quiñones de Benavente, sin fijar la culpa del hurto ${ }^{11}$.

Sean o no del mismo autor, por este camino no puede averiguarse nada, puesto que la atribución de los entremeses incluídos en aquel famoso rompecabezas bibliográfico que es la Segunda parte de Tirso se ha discutido casi tanto como la de sus comedias. Por consiguiente, hasta que no se descubran más datos, el autor de esta caricatura literaria de Ruiz de Alarcón ha de quedar anónimo.

Hannah E. De Bergman

Hunter College, New York.

\title{
LA FUENTE DE LAS HOJAS SECAS DE BÉGQUER
}

Gustavo Adolfo Bécquer sacó a luz en 1870, en el Almanaque literario del Museo Universal, su esbozo poético titulado Las hojas secas ${ }^{1}$. Esta breve obra, bella y melancólica, consiste en gran parte en un diálogo entre dos hojas secas que, detenidas por un momento, se cuentan sus recuerdos de otros días, cuando, besadas por el sol, se mecían alegres en el aire, reflejadas en las aguas transparentes del río; había insectos breves.

${ }^{8}$ No nos referimos aquí a los entremeses cantados o bailes, que suelen ser más

- En un tiempo creí ver otro inconveniente para la atribución de este entremés a Quiñones en la alabanza que del entremesista hace Alarcón en La culpa busca la pena (II, vir): "La comedia, felizmente, / aplaudida al puerto llega, / que era de Lope de Vega, / y el baile, de Benavente". Sin embargo, en un estudio reciente sobre esa comedia (NRFH, 7, 1953, p. 447), Courtney Bruerton llega a la conclusión de que estos versos, los únicos en el teatro de Alarcón en que se alude por sus nombres a poetas contemporáneos, fueron añadidos por otra mano que la del poeta mexicano.

${ }_{10}$ Op. cit., pp. $969-97^{\circ}$

11 "Entremeses del siglo xvil atribuídos al Maestro Tirso de Molina", ed. El Bachiller Mantuano, en Ateneo, 7 (1909), p. 74, nota.

1 Cf. Franz Schneider, "Tablas cronológicas de las obras de Gustavo Adolfo Bécquer", RFE, 16 (1929), p. 394 . 
brillantes, silfos que se columpiaban en los hilos de las arañas, jilgueros que colgaban de las ramas su nido de plumas... La vida de las hojas era un sueño de oro. En una hermosa tarde, dos amantes se detuvieron al pie del árbol que daba vida a las hojas:

Ella era joven, casi una niña, hermosa y pálida. Él le decía con ter. nura: - ¿Por qué lloras? -Perdona este involuntario sentimiento de egoísmo -le respondió ella enjugándose una lágrima-; lloro por mí. Lloro la vida que huye; cuando el cielo se corona de rayos de luz, y la tierra se viste de verdura y de flores, y el viento trae perfumes y cantos de pájaros y armonías distantes, y se ama y se siente una amada, jla vida es buena! - ¿Y por qué no has de vivir? -insistió él estrechándole las manos conmovido. -Porque es imposible. Cuando caigan secas esas hojas que murmuran armoniosas sobre nuestra cabeza, yo moriré también, y el viento llevará algún día su polvo y el mío quién sabe adónde ${ }^{2}$.

La noticia de que acabarían amarillas y secas llenó la noche de horror para las hojas. A poco desaparecieron los pájaros, las mariposas blancas y los insectos. Las escarchas tiñeron el follaje de varios colores y, al fin, los vientos dejaron desnudo el árbol. Desde entonces, las dos hojas han sido arrastradas entre el polvo y el fango. Una de ellas ha visto al amante de aquella hermosa tarde, que, ya vestido de luto, contemplaba distraído las hojas que daban vueltas en el agua turbia. Al fin una ráfaga vuelve a separar a las dos hojas secas.

El capítulo xviI ("Le manchon de Francine") de las Scènes de la vie de Bohème de Henry Murger³, una de sus partes más patéticas, cuenta la historia de los desventurados amantes Jacques y Francine; sus amores duraron sólo seis meses, pues la muchacha, que apenas tenía veinte años, ya sufría de tisis. Un amigo médico le había dicho al joven que su amiga moriría al marchitarse las hojas.

Un jour qu'ils étaient allés tous les deux à la campagne, Jacques aper. cut un arbre dont le feuillage était jaunissant. Il regarda tristement Francine qui marchait lentement et un peu rêveuse.

Francine vit Jacques pâlir et elle devina la cause de sa pâleur.

-Tu es bête, va, lui dit-elle en l'embrassant, nous ne sommes qu'en juillet; jusqu'à octobre, il y a trois mois; en nous aimant nuit et jour, comme nous faisons, nous doublerons le temps que nous avons à passer ensemble ${ }^{4}$.

La víspera de Todos los Santos, el viento arrojó sobre el lecho de la enferma la última hoja desprendida del árbol que se hallaba en el patio. Al día siguiente expiró la pobre Francine.

Como se ve, hay en las dos historias varias correspondencias: el tema del diálogo de los amantes en el campo; la cuita amorosa; el presenti-

2 BécQuer, Obras completas, Madrid, 1949 (col. Paradilla del alcor), pp. 392-393-

${ }^{3} \mathrm{La}$ publicación de esta obra comenzó el 9 de marzo de 1845 en Le Corsaire Satan, "petite feuille boulevardière", y duró más de cuatro años. Apareció en volumen en $185^{1}$ (cf. Georges Montorgueil, Henry Murger, romancier de la Bohème, Tours, 1929, pp. 186 y 202). Las Scènes describen la vida de los jóvenes de Montmartre durante la época romántica. Como se sabe, de allí tomaron Illica y Giacosa el argumento para su libreto de la ópera La Bohème (música de Puccini).

${ }^{4}$ Murger, Scènes de la vie de Bohème, Paris, 1897 (ed. de Oeuvres complètes), p. 222. 
miento de lo que ocurrirá en el otoño; la muerte de la muchacha después de la caída de las hojas amarillas; la desesperación del joven; las esperanzas marchitas; el tono melancólico y, finalmente, la importancia dada a las hojas secas ${ }^{5}$.

Para terminar, no me parece fuera de propósito recordar lo que dice Dámaso Alonso sobre el arte creador del poeta sevillano:

Bécquer tuvo, pues, como todo poeta, fuentes literarias de inspiración: la lejana, vaga y general de Heine; las muy directas de Byron y de Musset, y la cercanísima de José María de Larrea, y, de modo muy probable, muchas otras que no conocemos hoy y tal vez nunca serán descubiertas. Pero, como en todos los grandes creadores, la materia recibida llega a él sólo para ser trasfundida de manera prodigiosa. Lo añadido por Bécquer es siempre infinitamente más que lo que tomó. Esto era indiferente en absoluto: de cualquier sitio se podía alcanzar; materia sobre la que se pinta o con la que se plasma. Lo puesto por él sí que sería inhallable: la dardeante fantasía, la delgada sensibilidad, las luces más trémulas, la música de cuerdas dulcísimas o de juegos evocados de cristal y de agua, el irreal iluminado trasmundo de visiones, el hondo mundo poético de Gustavo Adolfo Bécquer.

HARvey L. JOHNSON

Indiana University.

5 El tema de las hojas secas no era nuevo ni pasajero en Bécquer. En San Juan de los Reyes (1857) el poeta divisa a Cisneros sentado en el claustro; es "la estación en que las amarillentas hojas de los árboles se desprenden unas tras otras... Las hojas secas arremolinadas a sus pies crujen al soplo helado del viento como cruje la falda de seda de una hermosa" (ed. cit., pp. 594-595; y cf. SchneIDER, art. cit., p. 394). En la rima 2 de las viejas ediciones (15 en el manuscrito del Libro de los gorriones) dice Bécquer:

$$
\begin{aligned}
& \text {... hoja que del árbol seca } \\
& \text { arrebata el vendaval, } \\
& \text { sin que nadie acierte el surco } \\
& \text { donde al polvo volverá... }
\end{aligned}
$$

(La mayor parte de las rimas se compusieron entre fines de $185^{8}$ y 1861: véase JuLro Nombela, Impresiones y recuerdos, Madrid, 1910, t. 2, p. 427; t. 3, p. 375). En su artículo Bailes y bailes (1864) exclama el poeta con dolor: "Desear que la juventud pase pronto... [es lo mismo que preferir a las mañanas de abril] las tardes desapacibles del otoño, con el fúnebre rumor de las hojas secas que el cierzo arrebata y confunde en un torbellino de polvo..." (ed. cit., p. 1247). Por otra parte, Bécquer recogió y publicó en el Almanaque literario del Museo Universal (1867) algunos poemas del desdichado Vicente Sainz Pardo, cuyos versos hablan asimismo de las hojas muertas que vagan perdidas a merced del viento. Véanse los poemas 1, 3, 4, 8 y 10 en Juan López NúÑ̃z, Bécquer, biografia anecdótica, Madrid, s. a., pp. 179-19o. José Pedro Díaz, G. A. Bécquer, vida y poesia, Montevideo, 1953, p. 267 , observa la semejanza de tono entre la rima 2 de Bécquer y el poema 10 de Sainz Pardo. Para mí, los dos poemas están estrechamente vinculados, y la influencia de Sainz Pardo resulta evidente si con la citada rima se comparan estos versos del poema 10: "†Hojas de marchitas flores! / con el aquilón pasad... // Id entre la seca arena / del abandonado erial / en revuelto torbellino / sin saber adónde vais... // Y hoy os arrebata el polvo / y os sacude el vendaval".

${ }^{6}$ D. Alonso, "Aquella arpa de Bécquer", en Cruz y Raya, núm. 27 (junio de 1935), pp. 95-96. 